\title{
Vadja koduhaldjate lemmikud ja vaenlased
}

\begin{abstract}
Enn Ernits
Teesid: Käesolevas artiklis annan ülevaate vadja koduhaldjast ja tema suhtumisest koduloomadesse, kaasates seni avaldamata ainest, mille moodustavad siinkirjutaja aastatel 1974-1982 Vaipoole vadjalastelt lindistatud kümme teksti. Vaatlen koduhaldjate nimetusi (domovikka jt), hüpostaase, tegutsemiskohti ja -aega, tegutsemisviise, armastatud ja vihatud koduloomaliike ning tõrjemeetmeid. Vadja domovikka võis esineda nii inimese kui ka looma kujul, kuid antropomorfsest koduhaldjast ei õnnestunud saada ühtki teadet. Müütiline koduhaldjas oli muutunud peaaegu tavaliseks nirgiks, kes häiris mitmeti hobuste, veiste ja lammaste heaolu. Ta ratsutas nende seljas, mistõttu loomad hakkasid higistama, lammastel langes vill välja jne. Olukorra normaliseerimiseks kasutati mitmesuguseid nirkide peletamise võtteid pahalõhnaliste ainete ja kellukesega. Vadja koduhaldja nimetustes ja uskumustes, mis on omavahel mitmeti põimunud, on palju ühisjooni teiste Ingerimaa rahvaste ja venelaste uskumustega.
\end{abstract}

Märksõnad: koduhaldjas, koduloomad, rahvausund, vadjalased

Vadjalased on eestlaste lähimaid hõimlasi. Vadja keelt kõneleb vaid mõnikümmend inimest Lääne-Ingeris, tänapäeva Leningradi oblasti Kingissepa rajoonis. See piirkond on pidevalt olnud ajaloo tõmbetuultes ja multikultuursusele avatud. Käesolevas artiklis annan ülevaate vadja kodu- ehk majahaldjast ja tema suhtumisest koduloomadesse, kasutades mh välitöödel kogutud seni avaldamata ainest.

\section{Kirjeldamise ja uurimise ajaloost}

Vadja uskumusi on esimesena ülevaatlikult kirjeldanud Paul Ariste ligemale kolmveerand sajandit tagasi. Ta käsitleb enda kogutud tekstide põhjal vadja koduhaldjat ja esitab eestikeelses tõlkes vadjalaselt Kikoria Kuzminilt kuuldud haldjaloo (Ariste 1932: 131). Hiljem on P. Ariste avaldanud mitmel puhul 
originaaltekste (nt Ariste 1977: 126-130). Rohkem kui tosin aastat varem oli Lauri Honko (1962) sulest ilmunud raamat Ingerimaa rahvaste uskumustest, milles ta mh vaatles kogu Ingerimaa kontekstis ka vadja ainest koduhaldja kohta. Umbes samal ajal liigitas asjaomase soome ainese Lauri Simonsuuri, kelle klassifikatsiooni laiendas hiljem Marjatta Jauhiainen (1998). Teiste läänemeresoome, samuti ka naaberrahvaste koduhaldjatest leidub kirjandust rohkesti.

Läänevadja koduhaldjast seoses koduloomadega on P. Ariste avaldanud kuus teksti, kuid üks sisult väga lähedane tekst on jutustatud kaks korda seitsmeaastase vahega (lisaks viitab uurija paarile avaldamata variandile materjalikogus). Julius Mägiste on talletanud kolm läänevadja teksti ja Elna Adler ühe teksti idavadja koduhaldjast (vt Adler 1968: 69-71; Ariste 1935: 14-15; 1941: 20; 1977: 127-129; Mägiste 1959: 31-32, 126-127, 199-200). Käesolevas kirjutises vaadeldakse ka isuristunud Kukkuzi murdetekstikest (Posti \& Suhonen 1980: 30). Seega saab arvestada vadja koduhaldja kohta seoses koduloomadega ühtekokku kümne avaldatud tekstiga, millest vanimad olid jutustatud alles 1930. aastatel.

L. Honko on oma monograafias kasutanud ka käsikirjalist ainest Santeri Ankeria, P. Ariste, M. Virolaineni jt kogudest (vt Honko 1962: 448-450). Seda materjali võib olla rohkemgi. Küsitletud keelejuhid olid sündinud aastatel 1858-1900.

Siinkirjutaja on aastatel 1974-1982 Vaipoole vadjalastelt kas üksi või koos Tiiu Ernitsaga lindistanud rahvapärase veterinaaria küsitlemise käigus kümme teksti. Järgnevad lühemad ja pikemad jutuajamised on litereeritud magnetofonilindilt (osaliselt mustandina) ja neid säilitatakse käsikirjalises kogus "Vadja loomakasvatust ja veterinaariat". Küsitletud keelejuhid (üks meesterahvas ja ülejäänud naised) olid sündinud ajavahemikus 1898-1912 vahemikus, seega olid nad lindistamise ajal eakad.

Tekstinäidetes on vajaduse korral esitatud küsimused toodud püstkirjas. Märk [---] tekstis tähistab väheolulise või arusaamatu teksti väljajättu. Autor kasutab kirjaviisi, mida võiks kasutada ka vadja kirjakeelena (vt Ernits 2006).

\section{Koduhaldjate nimetused}

Kõige sagedamateks vadja koduhaldja nimetusteks (kümnes külas) on venelaenulised domovikka ja domovikko, mida pole registreeritud idamurdest (vt tabel). Mõlemad vormid tulenevad sõnast dom 'kodu, maja'. Sõna domovikka esineb ka isuristunud Kukkuzi murdes. Sõna dvorovikka on regist- 
Tabel.Vadja koduhaldjate nimetused

\begin{tabular}{|c|c|c|c|}
\hline Koduhaldja nimetus & Kattila murre & Jõgõperä murre & Kabrio murre \\
\hline Domovikka, domovikko & $\begin{array}{l}+ \text { (Kat, Kõr, Lem, Sav } \\
<\text { Mat, Pum, Rud) }\end{array}$ & $\begin{array}{l}+ \text { + (Jõg, Lii, Luu, } \\
\text { Raj) }\end{array}$ & - \\
\hline Dvorovikka & + (Pum, Mat) & $+(\mathrm{Luu})$ & - \\
\hline Koo-peren-naa & $+($ Sav < Mat $)$ & - & - \\
\hline Koto-(h)altia $(z)$ & $+($ Lem $)$ & $+($ Jõg $)$ & - \\
\hline Ko $(t)_{o \text {-perem-meez }}$ & $+($ Kat $)$ & - & $+($ It $\check{s})$ \\
\hline Perem-meez & + (Mat) & - & - \\
\hline Tal(l)oo perem-meez & + (Mat) & $+(\mathrm{Luu})$ & - \\
\hline Tal(l)oo peren-nain & + (Sav < Mat) & - & - \\
\hline Õvvõõ peremeez & - & $+(\mathrm{Lii})$ & - \\
\hline
\end{tabular}

Külad: Itš - Itšäpäivä, Jõg - Jõgõperä, Kat - Kattila, Kõr - Kõrvõttula, Lem - Lempola, Lii - Liivtšülä, Luu - Luu(di)tsa, Mat - Mati, Pum - Pummala, Raj - Rajo, Rud - Rudja, Sav - Savvokkala

reeritud vaid kolmest Lääne-vadja külast. See on tuletatud sõnast $d v o r$ 'õu'. Peale selle tähistatakse koduhaldjat sõnadega altiaz, peremeez ja perennain. Liivtšüläst on talletatud dvorovikka otsese vastena õvvõõ peremeez (VKS; Ariste 1977: 126). Kui Põhja-Eestis kasutati haldjas-sõna ja LõunaEestis ema, isa jt, siis Lääne-Vadjamaal kasutati samaaegselt mitut nimetust, mis näitab, et germaani päritolu altiaz polnud genuiinseid nimetusi välja tõrjunud.

Kõige rohkem on koduhaldjanimetusi kirja pandud Kattila murdealalt. See seletub vähemalt osaliselt suhteliselt varase ja rohke ainesekogumisega Kattila kandis ning oludest tingitud ebapiisava kogumistööga Ida-Vadjas. Kolme nimetust kasutas keelejuht Olga Ivanova, kes oli läinud Matist Savvokkalasse mehele.

\section{Koduhaldjate portreed}

Vadja domovikka võis esineda nii inimese kui ka looma kujul. Kõigepealt antropomorfsest koduhaldjast. Sagedamini kujutati teda valgetes rõivastes naisterahvana. Mati keelejuht Olga Ivanova nägi koduhaldjat Savvokkalas naisterahvana, kes olnud üleni valges riietuses. Kuid leidunud ka meesterahvaid (Ariste 1977: 128-129). Itšäpäivä keelejuht silmanud ahjul lebades koduhaldjat naisterahva kujul, valge rätik peas (Adler 1968: 72-73). Valge mütsiga haldjast on üks teade isuritelt (Honko 1962: 268). Valge on teatavasti sakraalne, teispoolsuse ja esivanematega seotud värvus (Gura 1984: 133). Üleni valget rõivast peetakse Matti Sarmela (1994: 159) andmeil surisärgiks. 
Meesterahvana on haldjat kujutatud näiteks Luuditsas: hobusel olevat öösel ratsutanud peenikeste, käsivarrejämeduste jalgadega mees (Ariste 1977: 129). Siinpuhul assotsieerub kodukäija ilmselt surnud inimesest tekkinud painajaga (vrd samasugust tegelast ka liivi rahvausundis). Teise teate järgi näinud koduhaldjas välja nagu inimene, müts peas ja öökuub seljas (Mägiste 1959: 199-200).

Tunduvalt rohkem on onnestunud talletada teateid teriomorfsest koduhaldjast, kes esines enamasti nirgi, kuid ilmselt ka kärbi kujul (vdj la(a)ska, tšärppä; Kukkuzi kärppä; la(a)ska on teatavasti vene laensõna), kes on omavahel üsna sarnased, nii et tavainimene neid ei erista. Matis on tarvitatud mõistet koo-tšärppä 'kodukärp' (Honko 1962: 264). Sellistel lugudel oli ka ratsionaalne alus olemas, sest nirgid talvitusid sageli laudas, kus nad toitusid hiirtest ja võisid oma tegevusega loomi häirida. Kukkuzis on öeldud, et see pole tavaline $k \ddot{a r p p a ̈, ~ v a i d ~ v a l g e ~ j a ~ t e i s t e s t ~ v e i d i ~ v a ̈ i k s e m ~(P o s t i ~ \& ~ S u h o n e n ~}$ 1980: 30). Siin vist mõeldakse just nirki. Nii nirk kui ka kärp on talvel valge karvastikuga. Mitmed keelejuhid mainisid, et nirke on erivärvilisi. Kogetu tuleneb sellest, kas tegu on kärbi või nirgiga, samuti aastaajast. Siinpuhul võib lisada, et suvel on nirk ja kärp pealt punakaspruunid, kõhu alt valged, kirjuteks muutuvad nad karvavahetuse ajal. Must on vaid kärbi sabaots. Ent tundub, et vadjalased ei teadnud neid tõiku ja pidasid kõiki pisikesi väledaid "kärp-nirke" erinevateks liikideks. Kärplasi on osa keelejuhte ise näinud, osa mitte. Kujutelm nirgist koduhaldjana on levinud peale Ingerimaa rahvaste Eestis (peamiselt maa kaguosas), Karjalas, Ida-Soomes, Venemaal, Ukrainas, Valgevenes, Poolas ja Slovakkias (Hako 1956: 26-27).

En õlõ nähnüd. A on inemized nähtü. Tämä on valka, valka, pikkarain 'Ma ei ole näinud. Aga inimesed on näinud. Ta on valge, valge, väike' (VLV 1982, DMih, 19 < Jõgõperä - Dunja Mihhailova (1910)).

Õlõtta izze toožõ nähnü?

- Emm nähnüd, a tšärppää emm nähnüd. Vahtizimma, $i$ meez ôli veel eloz, vahtizimma, emm nähnüd kõns tätä, a senee tään, što lehm õli nii märtšä niku roho. Näd-ku oomnikkoss meed, kasõ on maaz. I siiz tämä ôli imennü kaglaa päält da niskaa päält. Ne ôltii nii lippeäd, märgäd.

'Kas olete ise ka näinud?

- Me ei ole näinud, kärpi ei ole näinud. Vahtisime, ja mees oli veel elus, vahtisime, me ei ole näinud teda kunagi, aga seda tean, et lehm oli nii märg nagu rohi. Näed kui hommikul lähed, kaste on maas. Ja siis ta oli imenud kaela pealt ja kukla pealt. Need olid nii libedad, märjad' (VLV 1982, NNes, 29 < Luuditsa - Nasto Nesterova (1904)). 


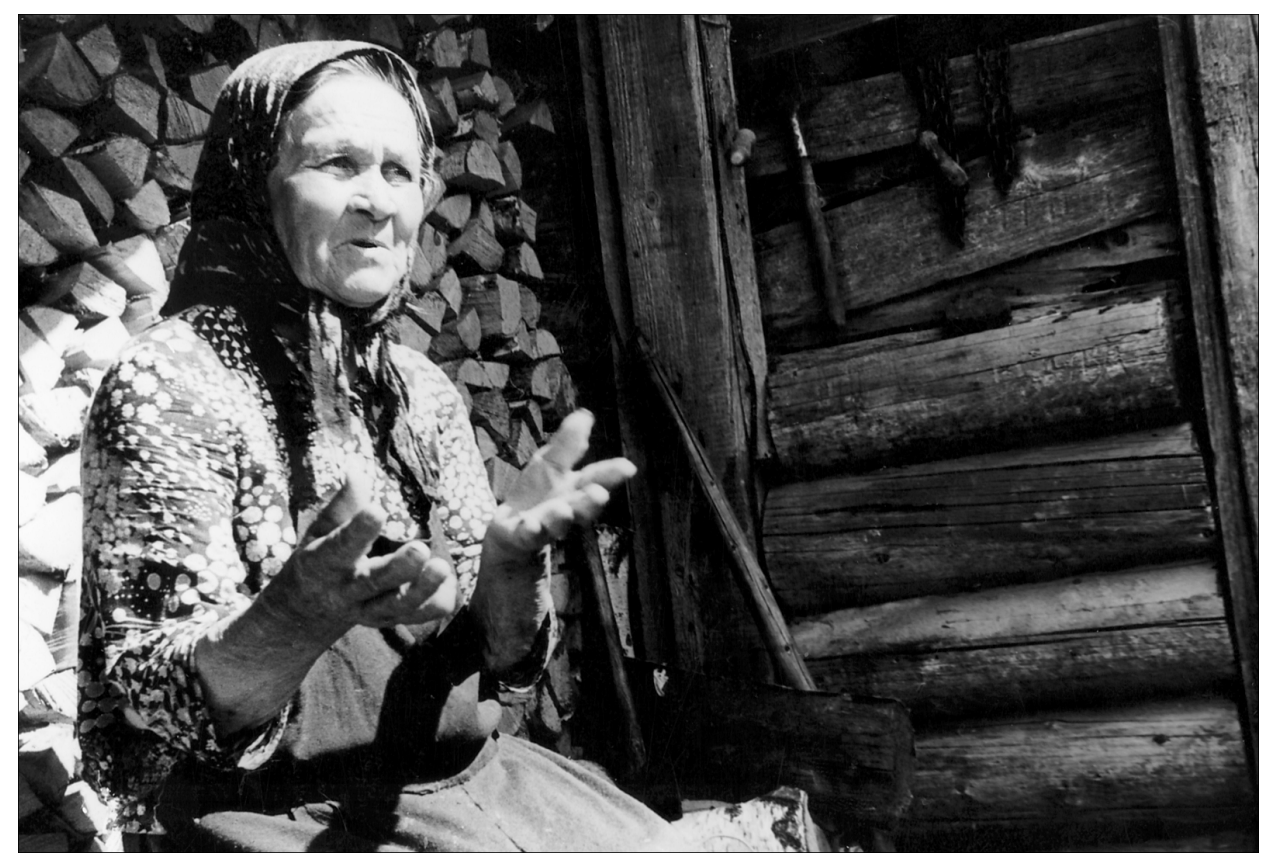

Foto 1. Nasto Nesterova Luuditsast 1981. aastal. Enn Ernitsa foto.

On nähtü toožõ?

- Jaa. Tämä ono pikkarainõ, ebõõ suuri. Tõin karva piti, milliss karvaa tämä tahob. Näd mõnikkaad on nähtü. Mõni perem-meez on nähnü õmaa õvvõz. Milliss karvaa tämä on, siis tämä mokomaa karvaa tahob. Neit on ruskait, $i$ on valkait, $i$ on tširjuit. On, milliss karvaa tämä tahob.

'Kas on ka nähtud?

- Jaa. Ta on väike, pole suur. Teistsugune värvus pidi olema, millist värvust ta on. Vaat mõned on näinud. Mõni peremees on näinud oma laudas. Millist karva ta [ise] on, siis samasugust värvust ta tahab. Neid on pruune, ja on valgeid, ja on kirjusid. On, millist värvust ta tahab' (VLV 1974, NLeo, 20 < Liivtšülä. - Nad'oža Leontjeva (1898)).

Laska on valkõa vai...?

- Valkõa. On neit i tširjavia, on i valkoi.

'Kas nirk on valge või...?

- Valge. On neid nii kirjusid kui ka valgeid' (VLV 1976, KLeo, 27 < Liivtšülä - Kostja Leontjev (1908)). 
Siinküsitletuist mäletas veel ainult Nasto Nesterova Luuditsast kärbi-nirgi vadjakeelset nimetust tšärppä. Mõnele keelejuhile ei tulnud esimese hooga ka venepärane nimetus meelde. Sel puhul küsiti talt otse, et jutt seetõttu pooleli ei jääks.

Milline zveeri se õli?

- Mokomain on vot.

Laska?

- Lask. Onki tämä mokoma niku orava. Mü̈̈ tapazimm näkemää meijee tanavalt $i$ mü̈̈ näimmä, ku jooksi silla-nallõ.

'Milline loom see oli?

- Vaat oli selline.

Nirk?

- Nirk. Ta ongi selline nagu orav. Me trehvasime nägema oma siseõuelt ja me nägime, kuidas jooksis põranda alla' (VLV 1976, NGeo, $22<$ Liivtšülä - Nat’u Georgijeva (1910)).

1943. aastal väitis üks Kõrvõttula keelejuht, et inimlaadsest koduhaldjast on kõneldud varem kui loomalaadsest (Mägiste 1959: 32). See on tõsi, sest ka allakirjutanu mitmed keelejuhid väitsid, et varem peetud laudaasukat koduhaldjaks, nüüd aga nirgiks. Siinkirjutajal ei õnnestunud enam talletada ühtegi teadet antropomorfse koduhaldja kohta. Küsimuse peale, kas looma ei piinanud haldjas, puhkes üks keelejuht valju häälega naerma. Siinkirjutaja kuulis küsimise peale peaaegu alati väidet, et varem peeti siseõues elavat olendit koduhaldjaks, aga tegelikult olevat see nirk.

Eb jutõltu, što domovikka?

- Eb, eb. Meijee aikana eb jutõltu.

'Kas ei öeldud, et domovikka?

- Ei, ei. Meie ajal ei öeldud' (VLV 1982, DMih, 19 < Jõgõperä - Dunja

Mihhailova (1910)).

A vana vätši eb juõllu, što domovoi?

- Noo, se jutõltii enne, što damovói. En tää, meill jutõltii što... tätä kutsutaa tšärppä, tšärpp, vennässi on laska, a maassi on tšärppe. Što se tšärppe ajõlõb i imeb sitä.

'Kas vanarahvas ei öelnud, et domovoi?

- Noo, nii (= see) öeldi varem, et damovói. Ma ei tea, meil öeldi... seda kutsutakse tšärppä, tšärpp, vene keeles on laska, aga maakeeles on tšärppe. Et see kärp ratsutab ja imeb teda' (VLV 1982, NNes, 29 < Luuditsa - Nasto Nesterova (1904)). 
A domovikka eb jutõltu?

- Domovikka, a perrä jutõltii, što se on lask. Lask, näd nütt johtu meelee. Lask.

'Kas domovikka ei öeldud?

- Domovikka, kuid pärastpoole öeldi, et see on nirk. Nirk, näed nüüd tuli meelde. Nirk' (VLV 1982, AJud, 28 < Luuditsa - Anna Judina (1906)).

Elokaz õli se vai haltiain?

- Se on tämä, jutôltii domovikka. Tämä on domovikka. A tämä on se lask, mikä on lask. Jaa. A meill enne-vanass jutõltii domovikk. Se ain... neit on kõikki karvaa. Mõnikkaad on valkaad, mõnikkaad on musad, siz on tširjuit, $i$ on ruskaid. Kõikkõlaisi on.

'Kas see oli loom või haldjas?

- See on see, öeldi domovikka. See on domovikka. Aga ta on see nirk, mis on nirk. Jaa. Aga meil öeldi ennevanasti domovikk. See on alati... neid on igat värvi. Mõned on valged, mõned on mustad, siis on kirjusid ja on pruune. Kõiksuguseid on' (VLV 1974, NLeo, $20<$ Liivtšülä Nad'oža Leontjeva (1898)).

A domovikka eb tšäünü lauttaasõõ?

- Domovikka. Eb [naerab] čäünü.

'Kas domovikka ei käinud laudas?

- Domovikka. Ei [naerab] käinud' (VLV 1976, NGeo, 22 < Liivtšülä Nat'u Georgijeva (1910)).

Üks huvipakkuv ja seni vajalikul määral kommenteerimata teade, mis on üles tähendatud 1943. aastal, pärineb Kõrvõttulast.

Domovikko nüt on tšärppä, se on niku lintu, miä näin tätä, lad'dad siived, mussa i valkõata näin 'Koduhaldjas on kärp, see on nagu lind, ma nägin teda, laiad tiivad, musta ja valget nägin' (Mägiste 1959: 31).

L. Honko (1962: 264, 284) peab nähtut jamaks, kuid venelaste uskumustes leidub ka lendavaid nirke. See kujutelm seostub neil pääsukesega, kelle sulestikus leidub nii musta kui ka valget; ka nimetused on sarnased, vrd лacka 'nirk' ja лacmo ıka 'pääsuke' (Petruhhin 1995: 243).

Mitmete rahvaste usundis on kujutelmad nirgikujulisest koduhaldjast ja majaussist segunenud. Järgnevalt näide Kukkuzist.

Kutsuttaz sitä mattoa domovikassi vai mokomain kärppä. Ikä taloz lääväz on mato. Ko ilmahub, siz mitä-nibit' pahennussa leeneb, a too hänt eb näü. On näht's'ü, että hään lehmä̈̈ maitua nännässä imeb 
'Kutsutakse seda madu domovikkaks, või selline kärp. Iga talu laudas on madu. Kui ilmub, siis tuleb midagi paha, aga muidu teda ei näe. On nähtud, et ta imeb lehmanisast piima' (Posti \& Suhonen 1980: 30).

Esimesel juhul on kindlasti tegu vene sõnalise ja usundilise kogunimetusega zadbl, kelle hulka kuuluvad paljud teispoolsusega seotud ktoonilised olendid, nagu konnad, ussid, maod, nirgid ja putukad, kes on tõenäoliselt ristiusu mõjul muutunud ebapuhasteks (Petruhhin 1995: 130-131). Seega pole see majauss, ent teisel juhul seostub just kujutelmadega laudaussist (lä̈̈vämato). Maahaldjaga seonduvat laudaussi, kes hammustab lehma udarat, on varem kirjeldatud Liivtšüläst (Honko 1962: 282).

Ühes ainulaadses loos nimetatakse kodukäijat vene sõnaga nasekomoje 'putukas' (Mägiste 1959: 126), mida L. Honko ja teised uurijad peavad samuti arusaamatuks. Ent vene uskumuses esineb koduhaldjas ka putuka kujul. Liiati tähistab vene murretes насеко иaя ka madu, sisalikku või konna (SRNG 1985: 157). Seegi kuulub zad $\iota$ seltskonda. Vene-eesti sõnaraamat annab peale sekundaarsete, inimest halvustavate sõnade tähendusteks muide '(igasugune) roomaja või kahepaikne' ja 'vastik loom või putukas' (VES 1984: 420).

Sageli võrreldakse koduhaldjat kassi (nt Mägiste 1959: 126; Ariste 1935: 14-15), ühel juhul isegi oravaga (Nat’u Georgijeva Liivtšüläst). Alati pole päris selge, kas tegu on hüpostaasi või ainult võrdluskujuga suuruse alusel. Ka vene uskumustes kuulub kass koduhaldja hüpostaasina kogunimetuse gadõ alla. Kassikujulisest koduhaldjast jutustavad ka isurid ja savakod (Honko 1962: 264). Nii vadjalased kui ka isurid on koduhaldjast jutustades maininud kord kassi (ilmselt siis täiskasvanud looma), kord kassipoega. Viimasel juhul tuleks oletada nirki, kes on kärbist tavaliselt väiksem (vt Aul \& Ling \& Paaver 1957: 231, 233).

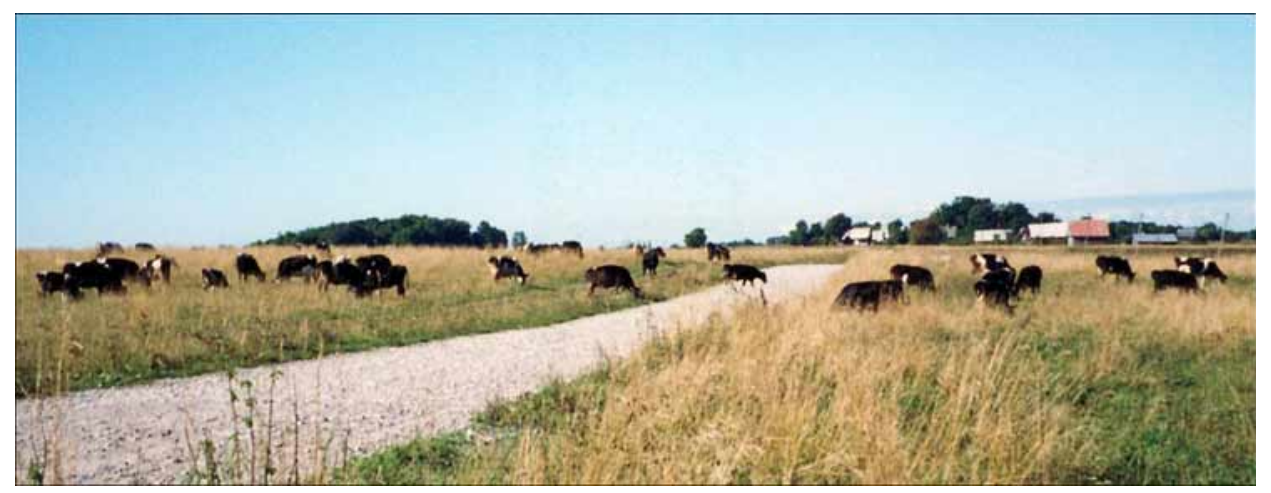

Foto 2. Veisekari Ida-Vadja küla Iivanaisi lähedal 2001. aastal. Koduhaldjas karjamaal loomi ei vaevanud. Enn Ernitsa foto. 


\section{Tegutsemisaeg ja -koht}

Vadja koduhaldjas elas väidetavasti igas majapidamises, kuigi teda enamasti ei nähtud. Parem oligi, kui tema olemasolu talus ei märgatud, sest tema ilmumine ennustanud halba (vt Kukkuzi näidet eespool). Mõnel juhul koduhaldjat siiski märgati. Näiteks Pummalas jutustati, et naaber ütelnud, et haldjat ei saa näha, kuid isa pugenud ööseks sõime alla peitu ja näinud teda (Ariste 1935: 14).

Vadja domovikka elas nii elumajas, loomalaudas kui ka siseõues. Loomadega seostuvad vaid kaks viimast. Siinpuhul tuleks tunda vadja toonast majapidamist ja sellega seonduvat sõnavara. Loomalaut (lautta; Kukkuzi läävä) ja kaetud siseõu (õvvi; Luuditsa tarha; Luuditsa, Kukkuzi tanava) moodustasid omaette terviku, mida nimetati sageli samuti õvviks. Laut oli mõeldud veistele, lammastele ja sigadele. Hobust peeti kas laudas või tallis (talli); viimase nimetuse seostamisest koduhaldjaga pole siinkirjutajal teateid. Üsna sageli hoiti suksut siseõues (Ränk 1960: 49). Vaadeldavast 20 tekstist pole seitsmel juhul koduhaldja asukohta üldse mainitud, kuuel juhul on tegu laudaga (lautta - 5; lääv $\ddot{a}-1$ ) ning seitsmel juhul siseõuega, mis neljal korral on ootuspäraselt seotud hobustega. Viiel korral on hoone nimetuseks olnud õvvi, ülejäänud kahte nimetust on kasutatud vaid ühe korra. Mõnes tekstis on nimetatud mõlemat hoonet (Posti \& Suhonen 1980). Viimases tekstis tehakse erinevalt laudast siseõue puhul juttu peremehest, võib arvata, et siinpuhul peetakse silmas samuti hobust. Tekstidest, milles on viidatud ajale, ilmneb, et koduhaldjas - nagu muudki sellised tegelased - tegutseb ainult öösiti. See on inimeste eest varjatud, tabudega seotud aeg.

\section{Tegevus}

Vadja domovoi, kes tegutseb ka eluhoones, on osaliselt karjahaldjas. Ta teeb nii head kui ka kurja, sõltuvalt sellest, kas ta armastab teatud looma või vihkab seda. Kui talle loom meeldis, oli see väliselt terve, sileda ja läikiva karvkattega. Kui hobune oli talle meele järele, punus ta öösel selle laka palmikuteks (nt Adler 1968; Posti \& Suhonen 1980). Pummalast on kirja pandud üks vastupidine teade, millest selgub, et ko nõizõb arjaa pletittämää, sis tämä p suvaa tätä, a ko sirgob üvässi arjaa, sis tämä suvaab 'kui hakkab lakka palmitsema, siis ta ei armasta teda, aga kui silub ilusaks laka, siis armastab' (Ariste 1935: 14). Edasi on jutustatud, et haldjas suges hobuse 


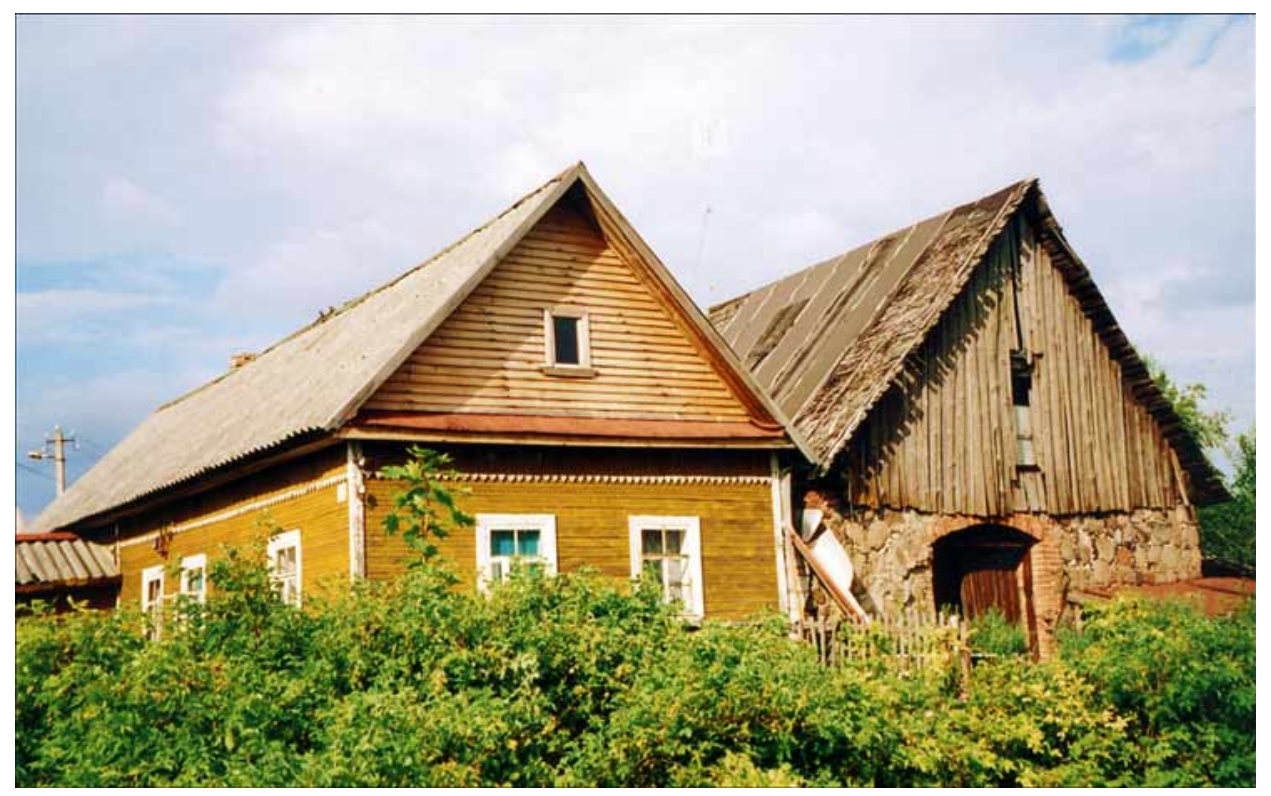

Foto 3. Majapidamine Matis 2003. aastal. Paremal on õvi laiemas tähenduses. Enn Ernitsa foto.

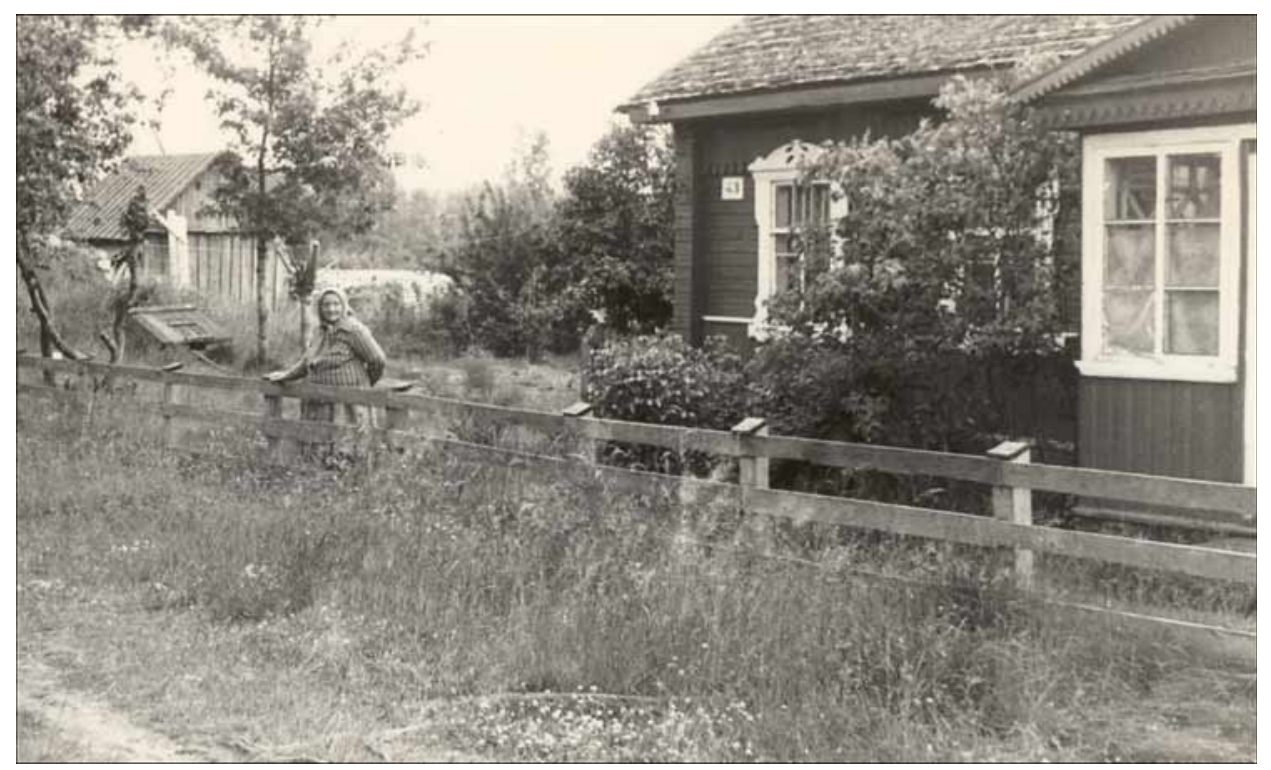

Foto 4. Domna Georgijeva Luuditsast 1982. aastal oma välisõuel (akkunalla, sõna-sõnalt 'akna all'). Enn Ernitsa foto. 
lakka nii, et tulesädemed langesid (tulizõt säteet karizõvad). See näib viitavat koduhaldja deemonlikele omadustele. Tavalisele vastupidist väidet tuli ette ka isureil (Honko 1962: 270).

Laka punumist esineb nii Lääne- kui ka Ida-Euroopas (Haavio 1942: 400401).Väideti, et loom peab olema sama värvi kui haldjas. Seepärast on räägitud mitut juhtu, kus haldja ja looma karva värvus ei ühtinud, mistõttu haldjas vihanud sellist olendit.

Nii ajõlõb, što õpõnõ on märtšä, kõik vaaoz. Kui bõõ sitä karvaa. I lehmäd on sitä-viisii toožõ. Ni ôllaa, meed oomnikoss lauttaa, märtšä, kõik vaaoz. Ko tahob sitä karvaa, milless tämä õvvõ... tahob kõik karvaa, eb taho. Sitä on ôllu 'Nõnda kihutab, et hobune on märg, kõik vahus. Kui ei ole seda karva [= värvust]. Ja lehmad on samuti sedaviisi. Nii on: lähed hommikul lauta, märg, kõik vahus. Kui tahab seda värvust, millega ta lauta... tahab kõik värvust, ei taha. Seda on olnud' (VLV 1974, NLeo, 20 < Liivtšülä - Nad'oža Leontjeva (1898)).

Õpõzõõ seltšää issuz i vaa ajõli [---] niku kissa. [---] hänen mukka oli hepoin. [---] mokomain õpõnõ on hänee mukka, meil õli mokoma linaharja hepoin. Tarhaz õli, rõõgatti, $i$ siin ajõli 'Hobuse selga istus ja ainult kihutas ringi [---] nagu kass. [---] tema moodi (=järgi) oli hobune. [---] selline hobune on tema moodi, meil oli selline linalakk-hobune. Oli siseõues, lõõtsutasid, ja kihutas siin ringi' (VLV 1982, DGeo, 15 < Luuditsa - Domna Georgijeva ( 1900)).

Värvuse järgi eelistamist esineb vepslastel, mordvalastel, kuid ka Rootsis, Norras, Taanis, Saksamaal, idaslaavlastel, slovakkidel ja teistelgi rahvastel (Honko 1962: 265; Gura 1984: 143 jj). Siinpuhul on uskuja ilmselt lähtunud põhimõttest: sarnane meeldib sarnasele. Kui koduhaldjas ei armastanud mingit looma, põhjustas ta sellele mitmesuguseid haigusi: lehm või hobune kõhnus, karvastik läks sakru, loom oli sõnnikuga määrdunud, võis longata, andis vähe piima jms. Koduhaldja tegevuses võib eristada seitset loomade piinamise või häirimise moodust: 1 ) ratsutab või ajab üleni higiseks (kuus teksti), 2) lakub ja imeb higi, karva või villa (neli teksti), 3) kõditab looma (üks tekst), 4) lihtsalt häirib looma oma tegevusega, 5) teeb looma sõnnikuseks (eriti Jõgõperäl), 6) viskab hobuse jalgupidi sõime alla, 7) joob laudaussina udarast piima või hammustab seda. Kolme viimati mainitud tegevust siinkirjutaja ülestähendustes ei esine, küll leidub aga nende kohta andmeid publitseeritud ainestikus (vt Honko 1962: $274 \mathrm{jj}$ ).

Kõige rohkem on tekste, milles koduhaldjas ratsutab või ajab looma laudas jooksma ja trampima, mis paneb ta tugevasti higistama. Sel puhul kirjeldati, 
kuidas hommikul, omanik lauta minnes märkas, et loom on üleni märg. Alati tekstist ei selgu, kas nirk ajas looma taga või ratsutas tolle seljas, sest vadja ajõlla tähendab nii üht kui ka teist (vt VKS I: 89). Samadest tekstidest ilmneb usk, et haldjas on samaaegselt piinatava higi lakkunud või lausa imenud (vt ka eespool esitatud tekste), samuti kõditanud looma. Tõsi küll, viimasel juhul ei selgu, kas on tegu tahtliku (müütilise) kõditamise või juhusliku kõditunde tekitamisega (vt ka VKS III: 10 laaska all).

Zveeri, zveeri mikälee. Se ajab kõvassi tätä, vot, opõnõ meeb hikkee $i$ lehmä meeb hikkee. En tää, kui tätä ävitetää poiz toož̃o [---] što se žiivatta ain hüpib i hüpib i hüpib. I püürib, i tämä hikkeä imeb. I siiz tämä sitä hikkeä imeeb, se lask. Siiz tämä sitä imeb 'Metsloom, miski metsloom. See kihutab temaga kõvasti, vaat, hobune läheb higiseks ja lehm läheb higiseks. Ma ei tea ka, kuidas teda ära hävitatakse [---] et see koduloom hüpleb kogu aeg, hüpleb ja hüpleb. Ja pöörleb, ja imeb ta higi. Ja siis ta seda higi imeb, see nirk. Siis ta seda imeb' (VLV 1982, AJud, $28<$ Luuditsa - Anna Judina (1906)).

Lask ajab. Lask, mokomain, kannii pittš on se [näitab käega]. Tämä meneb imeb žiivatalt sitä karvoit i lehmää, kilitäb lehmää. Siiz lehmä tappab, nii kaugaa kõvassi tappab, et meneb [---] Se õli [---] lask mokomain, kannii suur, suur, $i$ valkaad ôlla $i$ harmaad ôlla. I tämä žiivattaa sitä segotab 'Nirk sõidab. Nirk, selline, just nii pikk on see. Ta läheb imema loomalt neid karvu ja lehma, kõditab lehma. Siis lehma tabab, nii kaugelt kõvasti tabab, et läheb [---] See oli [---] nirk selline, just nii suur, on nii valged kui ka hallid. Ja ta seda kodulooma häirib' (VLV 1982, DMih, 19 < Jõgõperä - Dunja Mihhailova (1910)).

Milla meni toožõ. Õli lehmä, ain meni üüllä märjässi. Jutôlla, se on mokomain lask. Kui tämä maassi on, kui tämä on? Unohdin maassi, kui tätä kutsutaa. Ajõlõb, jutôllaa. Nõizõb lehmälle seltšää ja kraabib vain lehmää nii kauga ku meeb se lehmä märjässi i hikessi, siiz tämä tätä imeb. Nõizõb tälle seltšää lehmälle, što lehmä eb saa kuika tätä aijaa poiz, a siiz täm täl imeb kaglass. Śto miä, miul ôli õma lehmä, kassin lauttazõ. Nütt mil bõõ lehmää. Nii sitä, siiz ku kõik imi, nii kõik õltii lippeäd karvad kõik, kannii i nii ôltiki suuss niku nänned. Kõik imi 'Mul läks samuti. Oli lehm, aina läks öösel märjaks. Öeldakse, et on selline nirk. Kuidas ta on maakeeles, kuidas ta on? Unustasin, kuidas teda maakeeles kutsutakse. Ratsutab, öeldakse. Läheb [= tõuseb] lehmale selga ja kraabib vaid lehma niikaua, kui see lehm läheb märjaks ja higiseks, siis ta seda imeb. Läheb talle, lehmale, selga, 
nii et lehm ei saa kuidagi teda minema ajada, aga siis ta imeb tal kaelast. Et mina..., mul oli oma lehm, siin laudas. Nüüd mul pole lehma. Nii seda..., siis kui kõik imes, nii kõik olid karvad kõik libedad, nõnda ja nii olidki suust (väljas) nagu nisad. Kõik imes' (VLV 1982, NNes, 29 $<$ Luuditsa - Nasto Nesterova (1904)).

Lask on [---] Tämä siiz hüppääb seltšää $i$ siiz ajõlõb tätä. No tämä siiz... Meijee taloz sitä bõllu. A miä õlõn kuullu sitä niku... meijee taloz sitä bõllu 'Nirk on [---] Tema siis hüppab selga ja siis kihutab temaga. No ta siis... Meie talus seda polnud. Aga ma olen kuulnud seda nagu... meie talus seda polnud' (VLV 1982, MVit, $2<$ Luuditsa Mari Vittong ( 1912)).

Juttu villa lakkumisest lammastel, mille tagajärjel see välja langeb, leidub kahes tekstis, mõlemad pärinevad Jõgõperält.

Mikälee, ain jutõlla, što mikälee mokom žiivatta ono mõnikkaz lauttaz, što laska. Tämä kõik liizib neit lampaita, veeri karva päält vällää 'Miski, ikka öeldakse, et miski selline loom on mõnes laudas, et nirk. Ta neid kõiki lambaid lakub, tuli (= veeres) karv seljast maha' (VLV 1974, NLuk, 30-31< Jõgõperä - Nat'u Lukina (1898)).

Mokomain zveeri on lauttaz. Tämä käüb koko lampail selläz, koko ü̈̈tä, lammaz eb saa mittää tehä, siiz se villa lähäb vällää ja lammaz on märtš 'Selline metsloom on laudas. Ta käib kõigil lammastel seljas, kogu öö, lammas ei saa midagi teha, siis see vill tuleb maha ja lammas on märg' (VLV 1982, DRod, 2 < Jõgõperä - Dunja Rodionova ( 1903)).

Järgmisest katkest tundub, et nirk oma laudas viibimisega häiris looma rahu. Midagi salapärast siinpuhul ei toimunud.

Se on... taaz duumataa, što mikä on mokoma se lauttaz mokoma zveeri, mikälee tšäüb. Lehmällä eb anna spokoit, eb anna maata. No vot lehmä männööki märäks 'See on... jälle arvatakse, et miski on selline laudas selline metsloom, miski käib. Ei anna lehmale asu, ei lase magada. Noh, vaat lehm lähebki märjaks' (VLV 1976, NGeo, 22 < Liivtšülä Nat'u Georgijeva (1910)).

Asjaomased uskumused esinevad ka teistel Euroopa rahvastel. Näiteks nirk või teised loomad imevad lehma Saksamaal, Prantsusmaal (Hako 1956: 33 jj). Nirk kõditab ka Ukrainas ja Valgevenes ning muud mütoloogilised tegelased mujalgi (Gura 1984: 147 jj). Dmitri Zelenin (1991: 444) nimetab slaavi kodu- 
haldjatega seonduvaid lugusid rändmotiivideks, mis on teatavasti laialdase levikuga.

Siinkirjutaja ainesest selgub, et kõige sagedamini ratsutab nirk öösiti looma seljas, mistõttu see hakkab higistama. Ühes tekstis öeldakse, et $t a$ käib seljas kogu öo, kuid ratsutamisest otseselt juttu pole. Ratsutamist on seostatud ka higi imemisega, looma kõditamise ja muud moodi häirimisega.

\section{Armastatud ja vihatud koduloomad}

Meie keelejuhtide väitel oli koduhaldjatel tegemist kõige rohkem suurloomadega, kas hobuse või lehmaga.

Pummala ainulaadses teates lõpevad majapidamises seoses koduhaldja tegevusega kana, kaks siga ja lehm. Põhjuseks peeti seda, et talusse võidud visata kalmistult pärinevat liiva (Ariste 1977: 127-128). Seega usuti olevat tegu nõidumisega, mispuhul nõid sokutas majapidamisse liiva tabukohast, kust ei tohtinud midagi kaasa võtta.

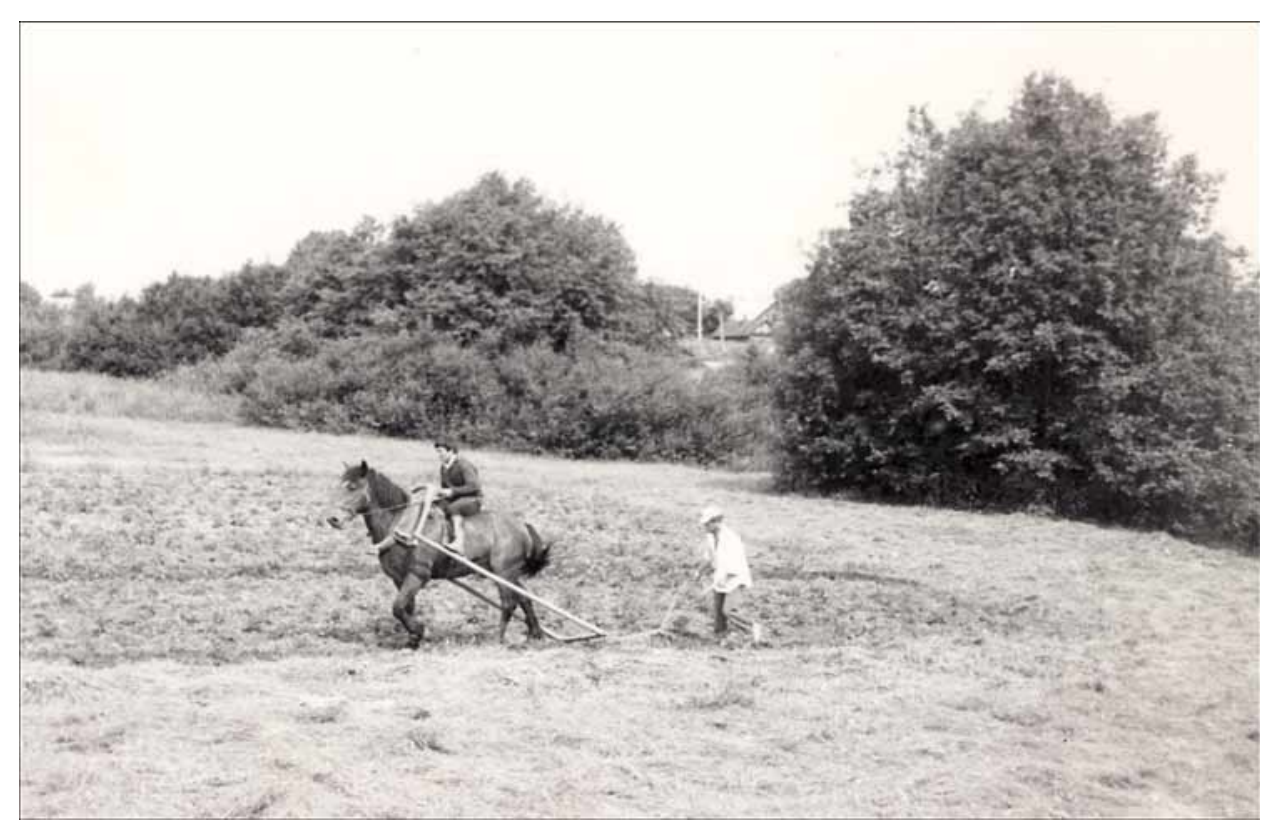

Foto 5. Tööhobusel ratsutas päeval inimene, öösel haldjas. Kukkuzi 1982. Enn Ernitsa foto. 


\section{Tõrjemeetmed}

Vadja aines sisaldab mitmesuguseid võtteid koduhaldja kahjulikust mõjust lahtisaamiseks. Varasemal ajal kasutati selleks kaht viisi. Esiteks, kui loom ei meeldinud haldjale värvuse poolest, müüdi hobune või lehm maha ja osteti uus, mis võiks sobida. Teiseks viisiks oli loomale laudas uue koha leidmine (Honko 1962: 290). Lepitusriitusi haldjaga pole teada. Keegi Luuditsa noormees üritanud öösel lehma seljas ratsutava antropomorfse domovikka isegi kangiga maha lüüa ning too haihtunudki silmist (Mägiste 1959: 200). Nirki on vadjalased püüdnud ka mürgitada (Honko 1962: 287).

Tarvitati vängehaisulisi jm peletusvahendeid, sest nirgi pühaduses, vähemalt veerand sajandi eest, juba tõsiselt kaheldi või seda eitati. Usuti, et olgu see loom või haldjas, küll vänge hais või muu selline ta minema peletab. Vahendeid toodi mh ka apteegist.

Siiz tarviz, mikä haizob kõvii, mokomain lekarstvo, mü̈̈ aptekiss tõimm. A bõllu aptekiss, siiz seneka, sitä valõta ümpär lehmää kanni viisii i tämä avitab [---] Siiz tarviz mokomaa, mikä haizob, sitä aptekiss meil õsõttii. Enne tehti babuškad, babuškad mikälee tehtii [--] 'Siis [on] tarvis, mis haiseb väga, selline ravim, me tõime apteegist. Aga kui apteegis polnud, siis sellega, seda valatakse lehma ümber niiviisi ja see aitab [---] Siis [on] tarvis sellist, mis haiseb, seda meil osteti apteegist. Varem tegid vanaemad, vanaemad tegid midagi [---]' (VLV 1982, DMih, 19 < Jõgõperä - Dunja Mihhailova (1910)).

Isegi loomaarst või velsker olevat andnud nõu laut petrooleumi ja piima seguga üle pritsida.

No mitä tehti. I miä karassiikaa, i vitirinaaral miä tšäin. Vitirinaara tšässi piimäkaa i karassiikaa siiz briizguttaa lehmää. Siiz miä en tšäünü 'No mida tehti. Ja ma petrooliga, ja ma käisin veterinaari juures. Veterinaar käskis piimaga ja petrooliga piserdada lehma. Siis ma (enam) ei käinud' (VLV 1982, NNes, 29 < Luuditsa - Nasto Nesterova (1904)).

Nirgi tõrjeks soovitati laudas pidada sokku. Seda on vänge haisu tõttu kasutatud muide ka Ida-Siberis (Zinovjev 1987: 308).

Kittsi, ku on kotonn, siiz laska eb tuõ. Laska eb tuõ siiz. Enne vet neil suuril herroloil, ku õli pal'l'o õpõzit ja lehmi, siiz nämä ain piettii kittsii, siäl õvvõz õli neill. Końušnoil ôli ain kittsi, suuri kittsi-boran, siiz õli boranaa haizoa, siiz lask eb tullu. Se borana... 'Kui kits on kodus, siis nirk ei tule. Nirk ei tule siis. Varem oli ju neil suurtel 


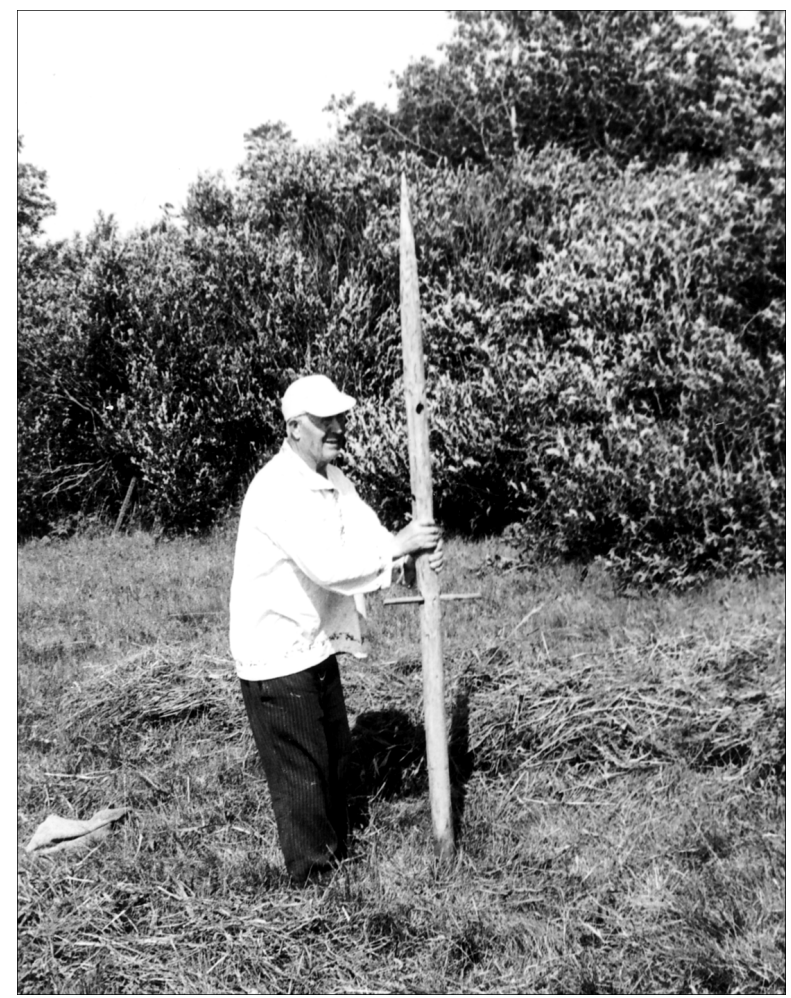

Foto 6. Kostja Leontjev Liivtšüläst 1981. aastal kärbist maasse löömas. Enn Ernitsa foto.

härradel (= mõisnikel), kui oli palju hobuseid ja lehmi, siis nad pidasid alati kitsi, seal laudas oli neil. Tallimeestel oli alati kits, suur sokk, siis oli sokuhaisu, siis nirk ei tulnud. See sokk...' (VLV 1976, KLeo, 27 < Liivtšülä - Kostja Leontjev (1908)).

Lamba selga pandi nirgi tõrjumiseks ka tubakat jm haisvat. Tubakat kasutasid üsna universaalse ravi- ja tõrjevahendina ka naaberrahvad.

Siiz pantii tubakkaa sinne, lampaa seltšää ja kõikkalaizõd lekarstvod sinne, tämä menneiz väl'l’ää, aisois.

- I avitti?

- No kõns avitti, kõns eb.

'Siis pandi sinna tubakat, lamba selga ja kõiksuguseid ravimeid sinna, [et] ta läheks minema, haiseks.

- Ja avitas?

- Noh, mõnikord (= millal) avitas, mõnikord ei' (VLV 1982, DRod, $2<$ Jõgõperä - Dunja Rodionova ( 1903)). 
Ka kästi loomale kaela siduda helisev kelluke, mis peletas nii pahavaime kui ka loomi. Liivtšüläst pärineb teinegi teade kellukese kasutamisest (Honko 1962: 289).

Laskõ tšäi. Miä en tää, pantii tšello kuilee kaglaa. Siiz eb tullu se domovikka. Enne vet kutsuttii, se ôli domovoi, duumattii, tšäävvä sinne 'Nirk käis. Ma ei tea, pandi vist kelluke kaela. Siis ei tulnud see domovikka. Varem ju kutsuti, see oli domovoi, arvati, käivad sinna' (VLV 1976, KLeo, 27 < Liivtšülä - Kostja Leontjev (1908)).

Siiz taaz tšäi. Siiz tšello tšäzittii panna kaglaa. Siiz miä panin kelloo

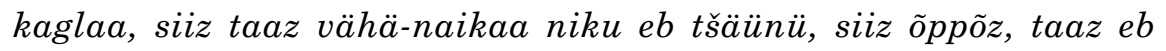
pelänüd [?] kelloa, siiz taaz nõistii tšäümää 'Siis taas käis. Siis kelluke kästi panna kaela. Siis ma panin kellukese kaela, siis taas vähe aega nagu ei käinud, siis õppis ära, taas ei peljanud kellukest, siis taas hakati käima' (VLV 1982, NNes, 29 < Luuditsa - Nasto Nesterova (1904)).

\section{Kokkuvõtteks}

Vadja koduhaldja nimetustes ja uskumustes, mis on omavahel mitmeti läbi põimunud, on palju ühisjooni teiste Ingerimaa rahvaste ja venelaste uskumustega.

Eesti painaja (elava inimese irdhing) käib painamas nii inimesi kui ka loomi. Vadjalastel on luupainaja enamasti surnud inimese hing, kes painab ainult inimesi. Koduhaldjas piinab või häirib aga koduloomi, eriti hobuseid ja veiseid. Tema laudast peletamiseks kasutati mitmesuguseid vahendeid (pahalõhnalised ained jm). Andmeid koduhaldjale ohverdamise kohta pole. 


\section{Arhiiviallikad}

VLV = Enn Ernitsa käsikirjaline ainekogu "Vadja loomakasvatust ja veterinaariat" (1970-1982)

\section{Kirjandus}

Adler, Elna 1968. Vadjalaste endisajast 1: Idavadja murdetekste. Tallinn: Eesti NSV Teaduste Akadeemia.

Ariste, Paul 1932. Vadja rahva usundist. Virittäjä 2, lk 127-145.

Ariste, Paul 1935. Wotische Sprachproben. Sitzungsberichte der Gelehrten Estnischen Gesellschaft 1933. Tartu: Gelehrte Estnische Gesellschaft, lk 1-85.

Ariste, Paul 1941. Vadja keelenäiteid. Acta et Commentationes Universitatis Tartuensis (Dorpatensis) B 49: 6, lk 1-92.

Ariste, Paul 1977. Vadja muistendid. ENSV Teaduste Akadeemia Emakeele Seltsi toimetised 11. Tallinn: Valgus.

Aul, Juhan \& Ling, Harri \& Paaver, Kalju 1957. Eesti NSV imetajad. Tallinn: Eesti Riiklik Kirjastus.

Ernits, Enn 2006 = Об обозначении звуков в водском литературном языке. Linguistica Uralica 1, lk 1-9.

Gura 1984 = Гура, Александр В. Ласка (Mustela nivalis) в славянских народных представлениях 2. Толстой, Никита И. (toim). Славянский и балканский фольклор: Этногенетическая обцность и типологчческе параллели. Москва: Наука, lk 130-159.

Haavio, Martti Henrikki 1942. Suomalaiset kodinhaltiat. Porvoo \& Helsinki: Söderström.

Hako, Matti 1956. Das Wiesel in der europäischen Volksüberlieferung mit besonderer Berücksichtigung der finnischen Tradition. Folklore Fellows Communications 56: 167. Helsinki: Suomalainen Tiedeakatemia.

Honko, Lauri 1962. Geisterglaube in Ingermanland 1. Folklore Fellows Communications 185. Studia Ingrica. Helsinki: Suomalainen Tiedeakatemia.

Jauhiainen, Marjatta 1998. The Type and Motif Index of Finnish Belief Legends and Memorates: Revised and Enlarged Edition of Lauri Simonsuuri's Typen- und Motivverzeichnis der Finnischen Mythischen Sagen (FF Communications 182). Folklore Fellows Communications 267. Helsinki: Suomalainen Tiedeakatemia.

Mägiste, Julius 1959. Woten erzählen: Wotische Sprachproben. Suomalais-ugrilaisen Seuran toimituksia 118. Helsinki: Suomalais-ugrilainen Seura.

Petruhhin 1995 = Петрухин, Владимир Я. (toim). Славянская цифология: Энииклопедический словарь. Москва: Эллис Лак. 
Posti, Lauri (koost) \& Suhonen, Seppo (toim) 1980. Vatjan kielen Kukkosin murteen sanakirja. Lexica Societatis Fenno-Ugricae 19. Helsinki: Suomalais-ugrilainen Seura.

Ränk, Gustav 1960. Vatjalaiset. Suomalaisen Kirjallisuuden Seuran toimituksia 267. Helsinki: Suomalainen Kirjallisuuden Seura.

Sarmela, Matti 1994. Suomen kansankulttuurin kartasto 2: Suomen perinneatlas = Atlas of finnish ethnic culture 2: Folklore. Suomalaisen Kirjallisuuden Seuran toimituksia 587. Helsinki: Suomalaisen Kirjallisuuden Seura.

SRNG 1985 = Филин, Федот П. \& Сороколетов, Федор П. (toim). Словарь русских народных гоһоров 20: Накучкать-Негоразд. Ленинград: Наука.

Zelenin 1991 = Зеленин, Дмитрий К. Восточнославянская этнография. Этнографическая библиотека. Москва.

Zinovjev 1987 = Зиновьев, Валерий П. (koost). Мифологические pacckaзы pycского населения Восточной Сибири. Новосибирск: Наука.

VES 1984 = Kull, Rein (koost) \& Leemets, Helle \& Saari, Henn (toim). Vene-eesti sõnaraamat 1 . Tallinn: Valgus.

VKS I-V = Adler, Elna \& Leppik, Merle \& Grünberg, Silja (toim) 1990-2006. Vadja keele sõnaraamat $=$ Словарь водского языка 1-5. Tallinn: AE Signalet \& Teaduste Akadeemia Kirjastus \& Eesti Keele Instituut \& Eesti Keele Sihtasutus.

\section{Summary}

\section{The Friends and Foes of Votian House Spirits}

\section{Enn Ernits}

Key words: house fairy, household animals, folk belief, Votians

The article aims to give an overview of the characteristics of Votian house spirits and the creature's attitude towards domestic animals and pets on the basis of so far unpublished ten texts recorded by the author from Votians in Vaipoole during 19741982. The article lists the names of house spirits (domovikka and others), hypostases, locations and time of activity, types of activity, the domestic animals that they were believed to favour and dislike and preventive measures used against them. The majority of names have been recorded in Kattila dialect. This could be, at least partly explained by the relatively early and abundant collection of the related material in the Kattila region and the insufficient collection in the eastern regions of Votia owing to the circumstances. The Votian domovikka dwelled in houses, cattle sheds, and in inner yards (ovvi). It may have assumed the shape of a human or an animal, although no account of an anthropomorphic house spirit could be obtained. The mythical house spirit had been transformed into an almost ordinary weasel or marten which disturbed the peace of horses, cattle and sheep at night. 
It is possible to distinguish between seven main ways of torturing or disturbing domestic animals in the behaviour of a house spirit: (1) it rides it or causes the animal to sweat (in 6 texts), (2) licks and sucks an animal's sweat, skin, or wool (in 4 texts), (3) tickles the animal (in one text), (4) generally disturbs the animal with its actions, (5) smears the animal with manure, (6) throws the horse by its legs under the manger, (7) steals milk from the udder or bites the udder. The three latter activities are not mentioned in the texts recorded by the author. As preventive measures against weasels various foul-smelling substances were used (paraffin, tobacco, goat stink) and a small bell was tied around their necks. The names and the interrelated beliefs about Votian house spirits share many common features with the beliefs of other Ingrian peoples and Russians. The material does not mention sacrifice to a house spirit. 